\title{
Damper Cage Loss Reduction and No-Load Voltage THD Improvements in Salient-Pole Synchronous Generators
}

\author{
S. Nuzzo*, M. Galea*, C. Gerada*, D. Gerada ${ }^{\dagger}$, A. Mebarki ${ }^{\dagger}$, N. L. Brown ${ }^{\dagger}$ \\ *Power Electronics, Machine Drives and Control Group, Univeristy of Nottigham,UK, eexsn16@nottingham.ac.uk \\ ${ }^{\dagger}$ Research and Technology Departement, Cummins Generator Technologies, Stamford, UK
}

Keywords: Salient-Pole Synchronous Generators, Damper cage, THD.

\begin{abstract}
Salient-pole synchronous generators (SG) have a long history of utilization as reliable power generation systems. Important aspects of such generators include a high power-to-weight ratio, high efficiency and a low cost per kVA output [1]. Another critical aspect is the requirement for very low harmonic content in the output voltage. Hence, it is very important to be able to model and predict the no-load voltage waveform in an accurate manner in order to be able to satisfy standards requirements, such as the permissible total harmonic distortion (THD). Also, at steady-state conditions, parasitic voltages are induced in the damper bars which lead to a current flow with associated power losses and an increase in temperatures. This paper deals with an in-detail analysis of a 4 MVA SG, whose operation is studied and compared with experimental results for validation purposes. The same platform is then used to propose innovative solutions to the existing design and operational challenges of the machine aimed at reducing ohmic loss in the damper cage and improving the output voltage THD, without reverting to disruptive techniques such as rotor and/or stator skewing.
\end{abstract}

\section{Introduction}

Being such a consolidated technology, today a wealth of literature exists stemming from the long years of utilisation of synchronous generators. However, today, there are much more demanding requirements from these machines which require considerable research effort in order to meet the technical and commercial demands. Innovation is required in order to make these machines more efficient in line with the increasingly stringent regulations for emission reduction and fuel savings. In addition, new grid codes and power electronic loads require innovative synchronous machine topologies and design. Recent developments in materials, manufacturing techniques, multi-physics modelling and advanced control also provide opportunities for improved performances, in line with these new requirements.

Among these aspects, particular focus has been given to the functional behaviour and the design features of the damper winding. This consists of bars placed in slots in the pole faces and connected together at each end. The end conductors in a 'complete' damper winding are closed rings (or sometimes end laminations) connecting the bars of all the poles, while for 'incomplete' damper windings they are electrically discontinued between poles. This additional winding is required in salient-pole synchronous generators for damping of torque oscillations, transient stability during unbalancedload operations and faults, reduction of parasitic air-gap harmonics, etc. [2].

Additional losses in the damper winding are due to the parasitic harmonics in the air-gap flux density. These harmonics are mainly due to the open slot structure typical of high-voltage machines and to the armature reaction magnetomotive force, which causes parasitic harmonics on the rotor surface when currents flow in the stator windings [3].

Traditionally, the design of damper windings has been done by combining theoretical and empirical techniques. Early works focused on estimating the damper-bar currents with the classical dq equivalent circuit approach $[4,5]$. With the same goal, permeance models based on Fourier expansion are proposed and developed in [6], [7], [8] and [9]. In [3], an innovative numerical integration method is proposed and this technique is also compared to the more traditional $\mathrm{dq}$ approach with very positive results. The worth of these traditional techniques is well known and their longevity has been consolidated by their use over many decades. However, with the recent advancements in computational capabilities, a significant shift towards numerical methods, such us finiteelement (FE) and computational fluid dynamics [10, 11], is slowly taking place. Such methods offer an increased accuracy and extra degrees of freedom in the design process. Due to this, today there is quite a revamped interest in the design of damper windings (and SGs in general) as this can be very beneficial to the overall SG design, especially when considering the possibility to investigate the performance both in steady-state and in transient conditions. In particular, "complete" and "incomplete" end connections are investigated in [12], [13] and [14], where the most important point to come out was predicting generator performance for various damper cage design alternatives. In [15] and [16], it was shown how FE analysis can be successfully used to achieve significant improvement in terms of the no-load voltage waveform.

In this paper, a particular 4 MVA SG is analysed and investigated using $\mathrm{FE}$ analysis. The $\mathrm{SG}$ in question is presented in Section 2, where it can be seen how the SG does exhibit high rotor losses. As a first step, a complete FE analysis of the current machine is done and the results 
compared with available experimental results. The FE model is then use to propose, investigate and validate a number of techniques to improve the overall SG performance.

The main objective of this work is to provide design recommendations, in order to reduce the damper cage loss at steady-state operation while keeping the no-load voltage THD under the set permissible limits.

\section{Analysis and validation of the model of the test platform}

The salient-pole SG under study is a four pole machine designed for stand-alone power applications. The machine has a rated apparent power of 4 MVA at a power factor equal to 0.8 . The $\mathrm{SG}$ is designed to provide a three-phase output voltage of $11 \mathrm{kV}$ at $50 \mathrm{~Hz}$. The stator is laminated and has an open-slot structure. Major features of the stator are the ventilating ducts in the core pack. These reduce the active material of the machine but increase cooling and airflow. The damper cage on the rotor is displaced around the centre line in alternating directions on each pole as shown in Fig. 1. This is to improve the harmonic content of the output voltage waveform in the absence of rotor or stator skewing.

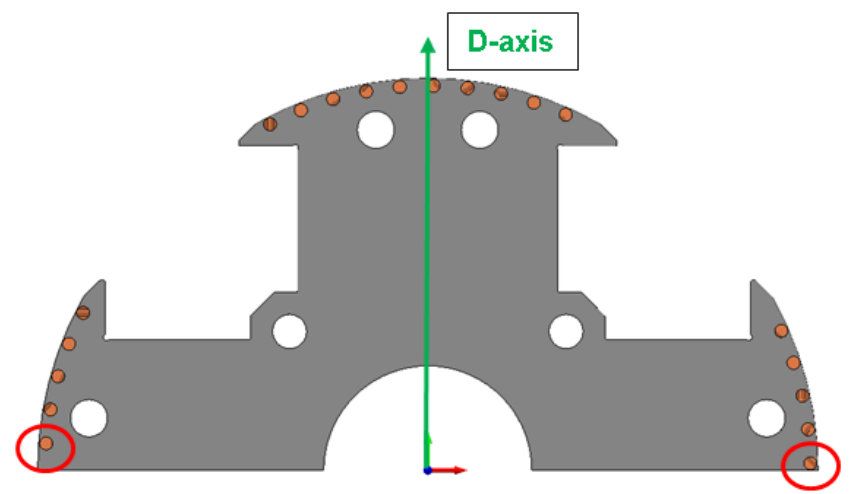

Fig 1: Current rotor topology with damper cage displaced around the d-axis.

In large synchronous generators, the presence of ventilating ducts along the axial length, the damper winding, the rotor laminations' support bars and their related stacking issues make the machine very complex to model and analyse. Other critical aspects are the leakage fluxes due to the end-windings and the presence of the end aluminium laminations needed to give continuity to the damper cage.

A FE model of the SG is therefore built. In order to be able to consider certain machine aspects (e.g. stacking and manufacturing factors) a number of compensation factors are included in the model (e.g. additional external resistances). This allows for a significant increase in the model's accuracy; however this exercise is not included in the paper as this would go beyond the scope of this work. As the main investigation focuses on the damper windings, it was considered essential to model the damper bars as accurately as possible. In fact, each damper bar is modelled as a solid conductor to take into account the skin effect due to the higher order slot harmonics.

\subsection{No-load and short-circuit characteristics}

The open circuit characteristic is found by measuring the noload terminal voltage at different levels of field current. Transient with motion simulations are used as these result in more accurate results since the harmonic content of the noload voltage is fully considered. Fig. 2 compares the FE results with the results achieved from an experimental prototype, where the similarity between the results can be observed.

The short-circuit characteristic is determined by measuring the steady-state current at different levels of field current after a sudden three-phase short-circuit fault at generator terminals. As can be observed in Fig.3, there is a very good agreement between FE and experimental results.

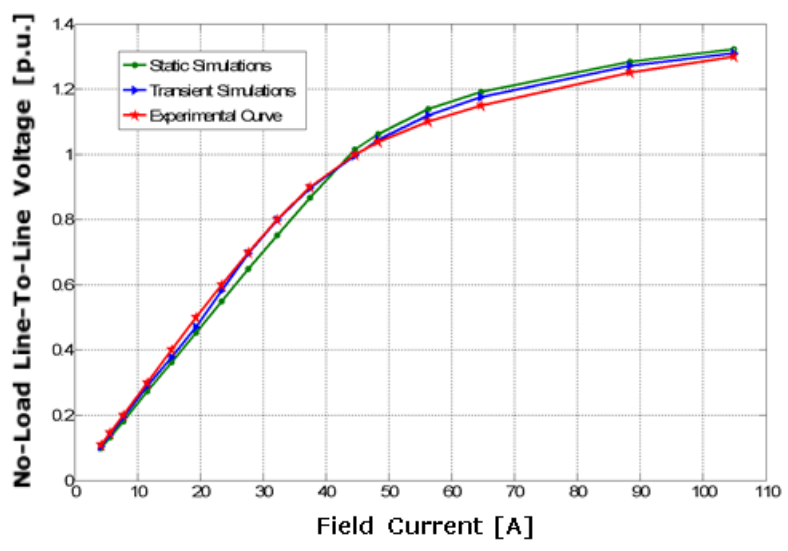

Fig 2: No-load characteristics - comparison.

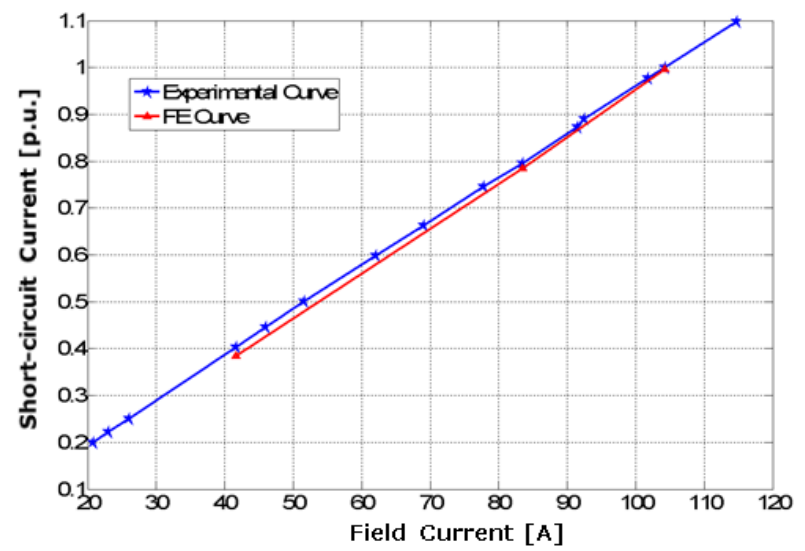

Fig 3: Short-circuit characteristics - comparison.

\subsection{Full-load analysis}

Fig. 4 illustrates the field distributions of the 4MVA SG at full-load conditions. The torsional effect of the transversal armature field component on the excitation field can be observed, due to the ohmic-inductive nature of the rated load. Table 1 compares the experimental and FE results for the full load condition, with excellent similarity being achieved, where the percentage error is always less than $1.5 \%$. 


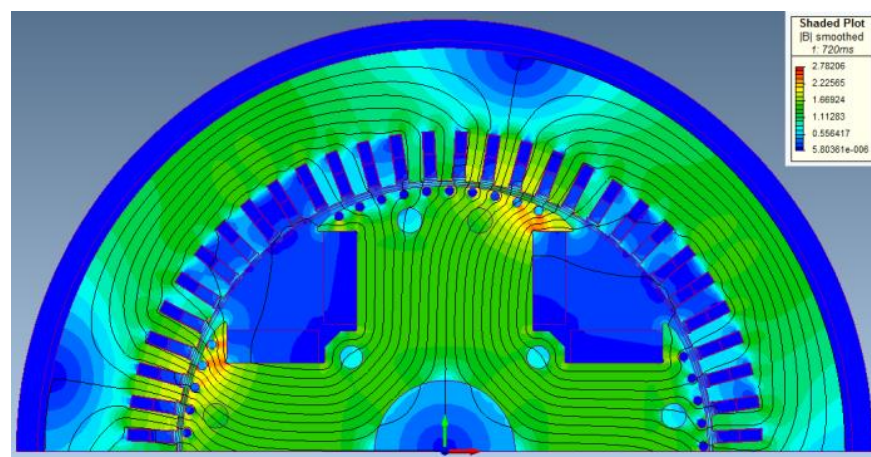

Fig 4: Field map at full-load condition.

\begin{tabular}{|c|c|c|c|}
\hline $\begin{array}{c}\text { Electromagnetic } \\
\text { quantities }\end{array}$ & $\begin{array}{c}F E \\
\text { Results }\end{array}$ & $\begin{array}{c}\text { Experimental } \\
\text { Results }\end{array}$ & $\begin{array}{c}\text { Percentage } \\
\text { Error }\end{array}$ \\
\hline Load Voltage & $10998 \mathrm{~V}$ & $11000 \mathrm{~V}$ & $0.02 \%$ \\
Phase Current & $230.2 \mathrm{~A}$ & $233.6 \mathrm{~A}$ & $1.46 \%$ \\
Power Factor & 0.802 & 0.8 & $0.25 \%$ \\
Real Power & $3508 \mathrm{~W}$ & $3560 \mathrm{~W}$ & $1.46 \%$ \\
\hline
\end{tabular}

Table 1: Full-load results - comparison.

\subsection{Power losses}

Power losses in electrical machines are composed by resistive losses in rotor and stator conductors, iron losses in magnetic materials and mechanical (windage and friction) losses.

\section{A. Copper loss}

The particular SG being considered for this work comprises the presence of ventilating ducts on the stator. Thus, in order to consider this, an additional lumped resistance is added to the model. This also used to take into consideration the endwinding effects (which can be important especially when considering 2D models). Simple corrections are included to take into consideration the temperature effects on the copper conductivity. Based on this, one may infer that the resistances considered in the FE model are very close to the experimental ones. Therefore, while no difference is detected for the field winding losses, the discrepancy between $\mathrm{FE}$ and experimentally determined stator currents (see Table 1) reflects on the stator resistive loss: the percentage error is therefore $2.89 \%$.

\section{B. Iron losses}

Core losses are experimentally measured at no-load and then assumed approximately constant for all load levels and power factors. Traditionally only the total core loss is determined as any localisation exercise to determine where the loss actually is (rotor or stator or damper) is very difficult to do. Although damper winding losses are of an ohmic-resistive nature, they are included in the experimentally measured value.

Numerical methods usually employ the Steinmetz equations to determine iron losses. In this case, an algorithm based on Steinmetz equations but extended to all the harmonics is proposed and implemented. Thus, surface losses due to the slot harmonics are properly considered over the whole amount of iron loss.

The model shown in Fig.4 is thus used to identify core losses at different loadings and power factors and the results are illustrated in Fig. 5. It can easily be observed that the iron losses are essentially constant in relation to the loading and power factor, while the damper cage loss significantly varies relative to these same aspects.

In order to be coherent with the experimental loss determination, the measured loss is compared to the predicted loss only for the no-load condition. A very good similarity with a percentage error of $13 \%$ between $\mathrm{FE}$ and experimental results were achieved.

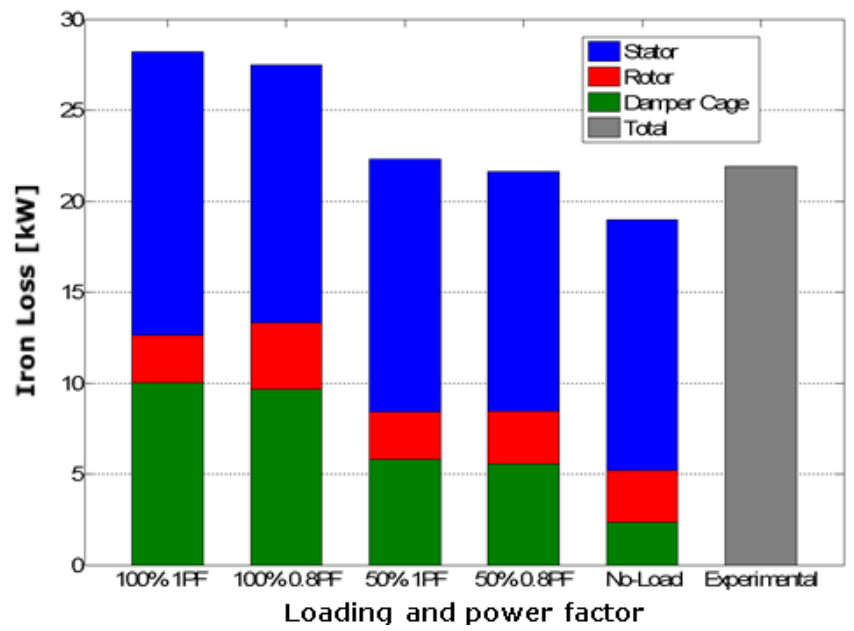

Fig 5: Losses at different load levels and power factors.

\subsection{Considerations on the FE model}

All the above confirms the validity of the built FE model of the 4 MVA generator. As can be observed, the results of the model when compared to the experimental results give an accurate match for each load condition. Fig. 2 and Fig. 3 show a comparison in terms of no-load and short-circuit characteristics. From Table 1, a very good agreement can be observed in terms of full-load results. Moreover, FE and experimental copper and iron losses are compared and successfully validated at different loadings and power factors.

\section{Damper cage loss considerations}

Having thus validated the FE model, the next step is to start considering more in detail the subject of the losses in the SG with special focus on the damper cage loss.

From Fig. 5, it can be observed how the damper cage loss is a very important contributor to the SG total loss for all load conditions. In particular, almost $30 \%$ of the total amount of rotor loss at no-load condition is due to the damper winding and $\approx 27 \%$ at full-load rated operation.

One of the main reasons for these elevated values of losses is the open slot geometry of the stator of the particular SG. Such a design indicates large variations in the air-gap flux (under the slot openings). The damper cage reaction to these variations results in excessive induced current flows in its 
bars, thus a considerable resistive loss is always present in the damper cage, even during steady state operation.

It is thus clear that in order to improve the existing design of the $\mathrm{SG}$, the issue of the damper cage loss must be addressed. A sensitivity analysis of the main design parameters that affect the damper cage loss is thus carried out with the key parameters investigated being

- $\quad$ The magnetic permeability of stator slot wedge

- The damper bar pitch

- Asymmetric displacement of damping bars around the d-axis

\subsection{Influence of the slot wedge permeability}

One way to reduce the heavy "slotting" effect on the air-gap flux density is using a different material for the slot wedge. In the actual machine the wedge material has a relative magnetic permeability equal to $2.5 \mathrm{H} / \mathrm{m}$.

By increasing the magnetic permeability of the slot wedge material, the slotting effect considerably decreases on both the rotor surface and the damper bars. Indeed the higher the permeability, the more isotropic is the stator surface which faces the main air-gap. The overall effect of this aspect was investigated by testing the FE model of the 4 MVA SG for a number of different slot wedge materials, each with its own permeability value.

Fig. 6 compares the radial air-gap flux density for six different magnetic wedge materials (including the one of the current design). As expected, the higher the permeability the smaller is the air-gap flux variation.

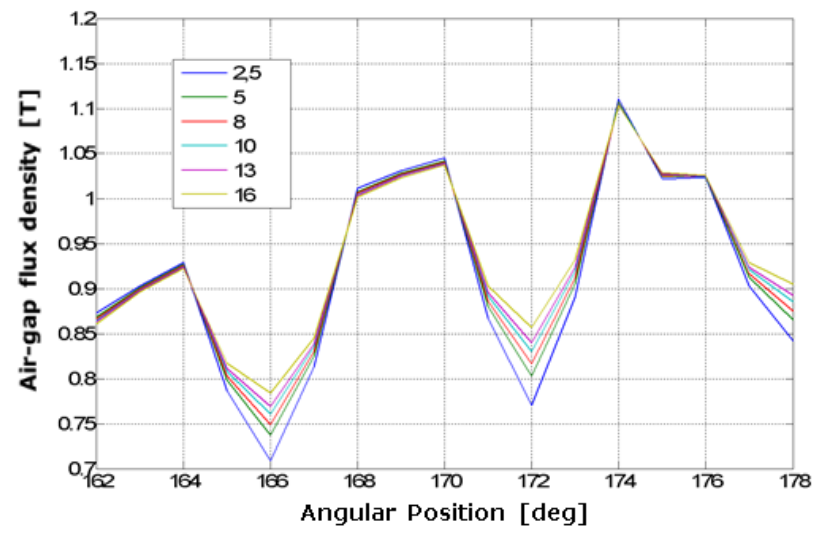

Fig 6: Zoom on radial air-gap flux densities - comparison among machines with different slot wedge materials.

From a loss perspective, Fig. 7 shows how for no-load, the cage loss decreases as the magnetic permeability of the slot wedge material increases. In fact, the damper cage loss is reduced by $40 \%$ when the permeability is equal to $10 \mathrm{H} / \mathrm{m}$.

Another perceived advantage is a THD reduction of the noload line-to-line voltage, as may be observed in Fig. 8.

At full-load condition, the damper cage loss is reduced by $\approx 33 \%$ when the permeability is $5 \mathrm{H} / \mathrm{m}$ and by about $42 \%$ if a permeability of $8 \mathrm{H} / \mathrm{m}$ or $10 \mathrm{H} / \mathrm{m}$ is used. As shown in Fig. 9, beyond these values no significant improvements are achieved.

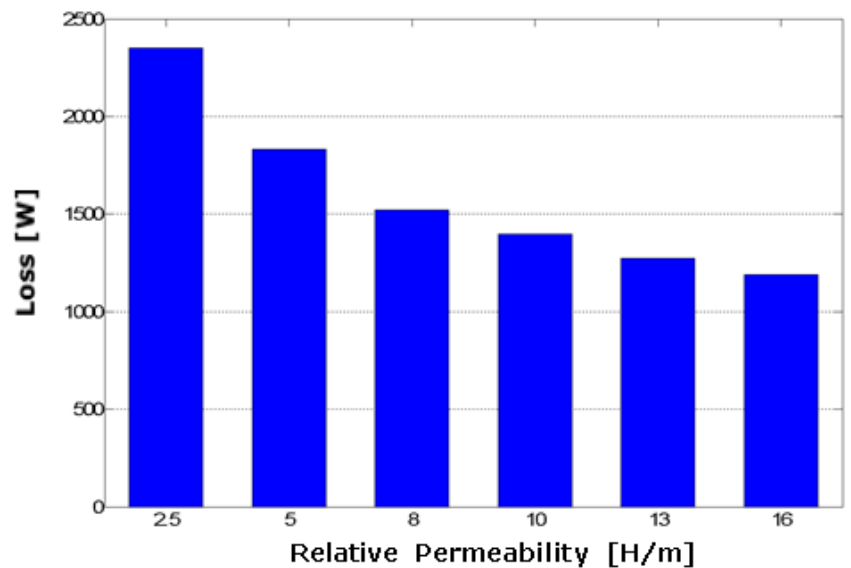

Fig 7: Damper cage loss trend with the variation of the slot wedge magnetic permeability at no-load operation.

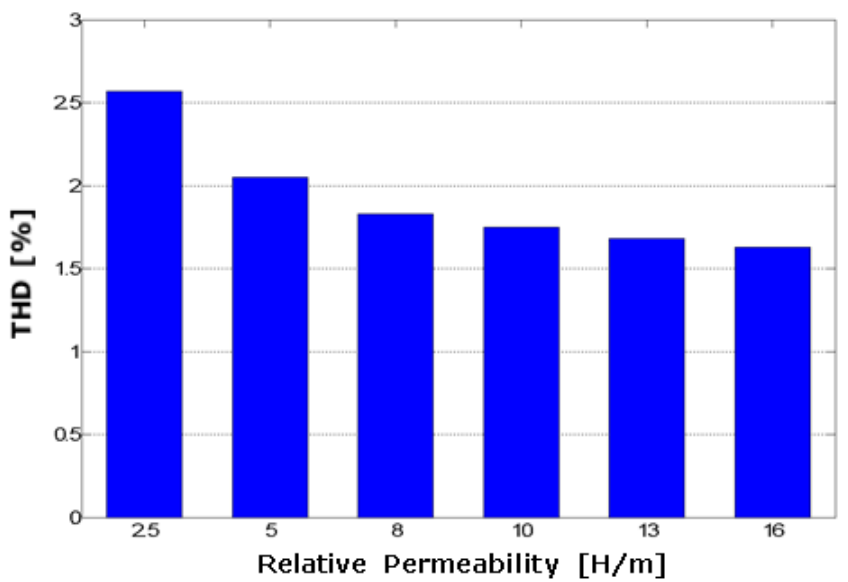

Fig 8: No-load line-to-line voltage THD trend with the variation of the slot wedge magnetic permeability.

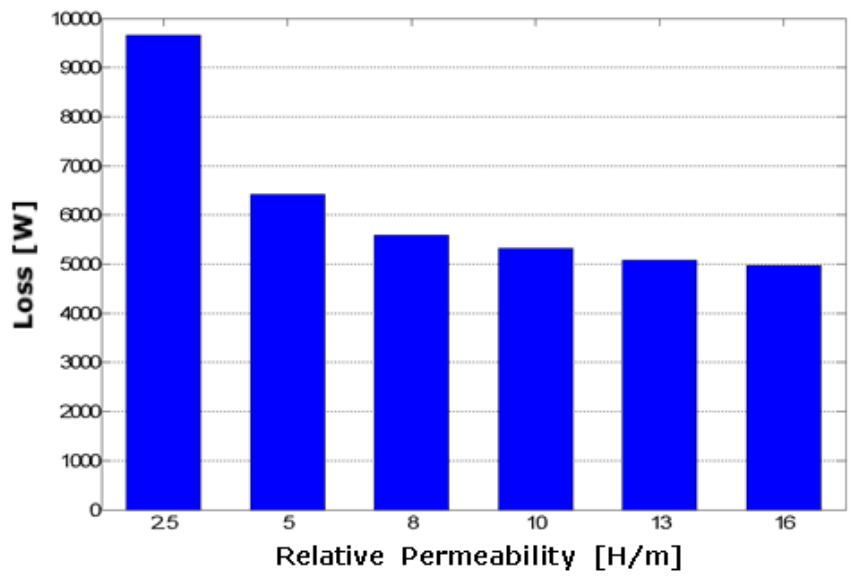

Fig 9: Damper cage loss trend with the variation of the slot wedge magnetic permeability at full-load operation.

The main drawback of increasing the permeability is the increase of slot flux leakage especially at full-load operating condition. This results in less useful flux crossing the air-gap and consequently a higher voltage drop and a torque 
reduction. Comparing the results of tests performed with 2.5 $\mathrm{H} / \mathrm{m}$ and $16 \mathrm{H} / \mathrm{m}$ materials, a voltage drop of $5 \%$ is found. This can be compensated by an increase of the excitation current, however at the cost of extra copper losses, which in turn can potentially negate the positive effect of having a higher permeability slot wedge material.

All this indicates that modifying the slot wedge material is a potential solution for reduction of losses with however a negative impact on the overall performance. More detailed trade-off studies applied to the particular application would be required in order to study the overall behaviour if such a modification was undertaken.

\subsection{Influence of the damper bar pitch}

Another important player in terms of damper cage losses is the effect due to the pitch of the damper bars, which strongly relates to the stator winding slot pitch. Traditionally, this is chosen by applying well-known rules of thumbs. However, with detailed modern analysis techniques, this also can be improved by a considerable margin.

In order to understand this aspect, the FE model is modified and implemented with varying of bar pitch with the damper cage being kept symmetric in respect to the polar axis. The results show no significant improvements respect to the case where the original bar pitch is used. On the contrary, the original bar pitch (i.e. $5.7^{\circ}$ ) is the most appropriate in terms of loss reduction, as one may note in Fig. 10.

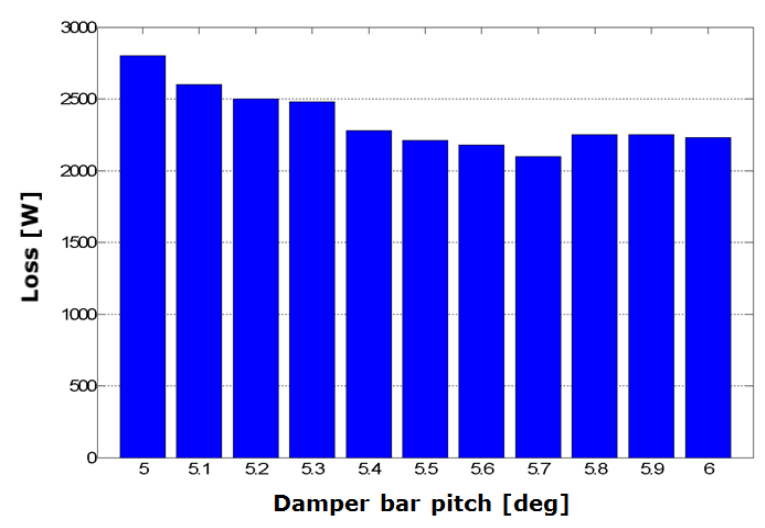

Fig 10: Influence of damper bar pitch on no-load losses.

\subsection{Influence of asymmetric displacement}

A known way how to improve the voltage THD is done by displacing the damper winding bars by a particular angle, usually chosen as a fraction of the stator slot pitch. This can be seen in Fig. 1 where it can be clearly observed that the damper bars are displaced in an asymmetric form over the rotor poles.

This concept is tested by implementing different positions of the damper bars along the azimuthal direction. The tests are performed in order to investigate the effects that asymmetry has on both the total amount of losses in the damper cage and voltage THD.

Fig. 11 shows that the original damper winding position ($\left.1.68^{\circ}\right)$ is the only one that achieves a THD lower than $3 \%$.
While this is a very important aspect (considering the importance of having a low THD for this application), however this is not an optimal solution, because as seen in Fig. 12, it also has considerable damper winding ohmic loss resulting in more heat generation and consequently a deterioration in the total machine efficiency.

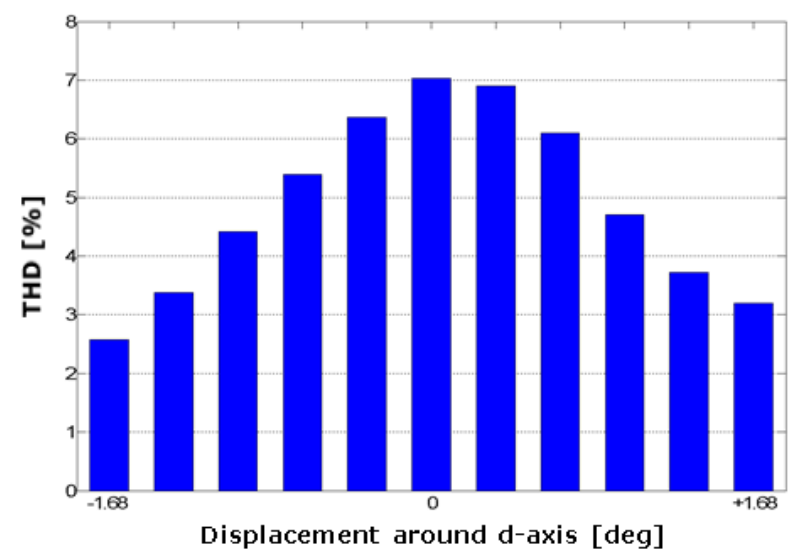

Fig 11: No-load voltage THD versus damper cage tangential position.

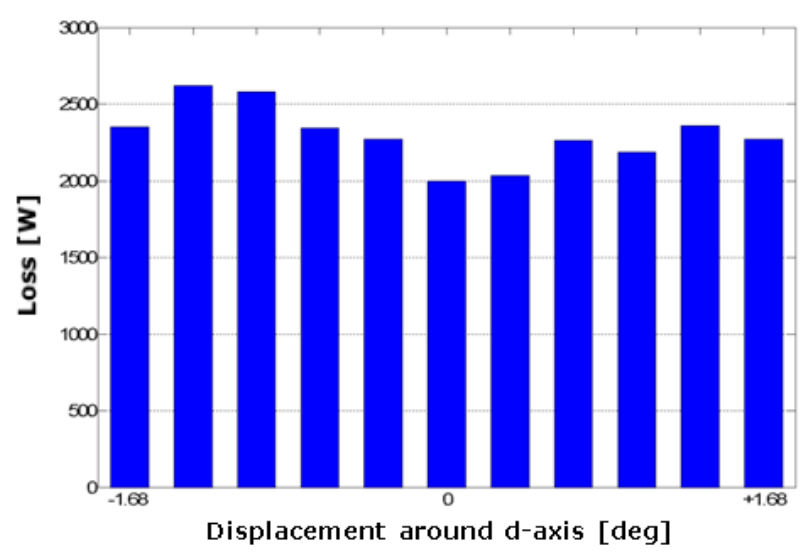

Fig 12: No-load damper cage loss versus tangential position.

\subsection{Conclusions on damper loss investigation}

Considering all the above, then it is clear that while the original design of the damper cage meets some of the requirements (THD <3\%), however, significant margins of improvement (mainly in terms of reducing losses) can be achieved.

In the next and final section of the paper, these aspects will be considered and recommendations given to reduce losses, while still keeping the THD under acceptable limits.

\section{Considerations on moving the damper winding position along radial and tangential position}

All the above studies have shown that for certain aspects there is significant room for improvement by modifying the design of the damper winding. Sections 3.2 and 3.3 in particular 
investigated moving the damper cage windings in the tangential direction. Considerable variations on the machine performance can also be achieved by increasing the distance of the damper bars from the air-gap, which means that the effects of the open slot configuration would be significantly reduced.

With all the above in mind, a sensitivity analysis of the damper winding position along the radial and the tangential directions, as shown by the red rows in Fig. 13, is carried out at the no-load condition.

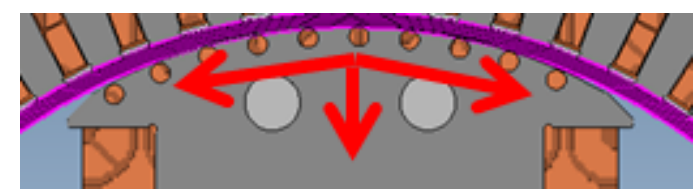

Fig 13: Parametrization of the damper cage position along radial and tangential directions.

As can be observed in Fig. 14, the losses in the damping bars are heavily affected by the radial distance from the air-gap. Fig. 15 shows the resulting total THD for the implemented variations of the radial and tangential position of the bars. It can be concluded that moving the bars further away from the air-gap by $1 \mathrm{~mm}$ for an optimal tangential position, the noload output voltage THD can be improved by $17 \%$, resulting in a damper winding loss reduction of $2.151 \mathrm{~kW}$ at no-load and $4.282 \mathrm{~kW}$ at full-load.

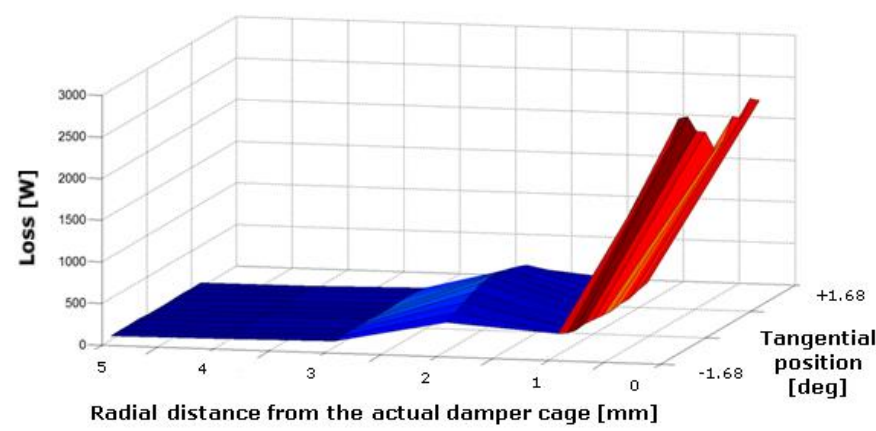

Fig 14: Damper cage losses versus radial and tangential positions.

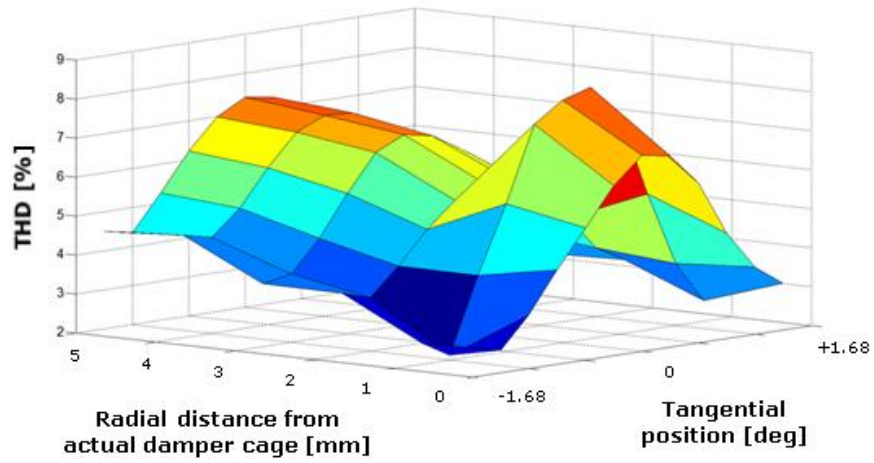

Fig 15: Voltage total harmonic distortion versus radial and tangential positions.

\section{Conclusion}

This paper investigates possible methods on how to reduce the damper cage losses and improve the output voltage THD for salient-pole SGs. As vessel to test this, a 4 MVA SG developed and manufactured by Cummins Generator Technologies was used. An important aspect of the paper is the use of modern numerical analysis methods which can result in much more accurate and improved solutions when compared to the traditional analytical and empirical methods, usually used for the design of SGs.

In this paper, it has been shown that

- The damper cage loss can be significantly decreased by using a stator slot wedge with an appropriate magnetic permeability. This however comes at the cost of a higher slot flux leakage (especially at fullload operating condition), which in turn propagates other negative effects such as torque reduction.

- The damper bar pitch affects the damper cage loss. For the 4 MVA SG, it was concluded that the original damper pitch of $5.7^{\circ}$ can be considered as the optimal value in terms of loss minimisation.

- There is a very close relationship between the voltage THD and the tangential position of the damper cage. This does produce improvements on the voltage shape; however it also results in higher losses and produces overheating issues.

Considering all this, it was concluded that very important benefits can be achieved by moving the bars along the radial and the tangential directions. It was shown how by increasing the distance of bars from the air-gap by $1 \mathrm{~mm}$ and placing them in the appropriate tangential position, then the no-load output voltage THD is improved and the damper winding losses are reduced by $2.151 \mathrm{~kW}$ at no-load and $4.282 \mathrm{~kW}$ at full-load.

\section{References}

[1] K. S. Jiji, N. H. Jayadas, C. A. Babu. "FEM-based Virtual Prototyping and Design of Third Harmonic Excitation System for Low-Voltage Salient-Pole Synchronous Generators," IEEE Trans. Ind. Electron., vol.50, no. 3, May/June 2014.

[2] E. Kimbark. "Power System Stability - Volume I," WileyIEEE Press, Chapter XIV, pp. 214-246, 1995.

[3] G. Traxler-Samek, T. Lugand, A. Schwery. "Additional Losses in the Damper Winding of Large Hydrogenerators at Open-Circuit and Load Condition," IEEE Trans. Ind. Electron., vol.5, no. 1, pp. 154-167, Jan. 2010.

[4] M. M. Liwshitz, T. Lugand, A. Schwery. "Harmonics of the salient pole synchronous machine and their effects Part III. Differential leakage of the damper winding with respect to the main wave. Current distribution in the damper bars," Trans. Amer. Instr. Elect. Eng. Part III Power App. Syst., vol.77, no. 3, pp 462-469, Apr. 1958.

[5] I. M. Canay. "Calculation on negative-sequence losses and negative-sequence resistance of turbogenerators," 
IEEE Trans. Power App Syst., vol.PAS.94, no. 3, pp. 764-773, May 1975.

[6] I. H Karmaker, A. M. Knight. "Calculation on negativesequence losses and negative-sequence resistance of turbogenerators," Proc. 16th ICEM, 2004, pp. 1-5.

[7] I. H Karmaker, A. M. Knight. "Investigation and simulation of fields in large salient-pole synchronous machines with skewed stator slots," IEEE Trans. Energy Convers., vol.20, no. 3, pp. 604-610, Sep. 2005.

[8] A. M Knight, I. H. Karmaker, K. Weeber. "Prediction of damper winding currents and force harmonic components in large synchronous machines," in Proc. $15^{\text {th }}$ ICEM, 2002, p. 35.

[9] A. M Knight, I. H. Karmaker, K. Weeber. "Use of a permeance model to predict force harmonic components and damper winding effects in salient-pole synchronous machines" IEEE Trans. Energy Convers., vol. 17, no. 4, pp. 709-716, Dec. 2002.

[10] P. H. Connor, S. J. Pickering, C. Gerada, C. N. Eastwick, C. Micallef, C. Tighe, "Computational fluid dynamics modelling of an entire synchronous generator for improved thermal management," Electric Power Applications, IET, vol. 7, no. 3. pp. 231-236, 2013.

[11] P. H. Connor, S. J. Pickering, C. Gerada, C. N. Eastwick, and C. Micallef, "CFD modelling of an entire synchronous generator for improved thermal management," Power Electronics, Machines and Drives (PEMD 2012), 6th IET International Conference on. pp. 1-6, 2012.

[12] E. Shlemmer, G. Ofner. "Finite-element investigations of the transient behaviour of salient-pole synchronous machines with different damper end connections," presented at Int. Conf. Electrical Machines (ICEM), Vilamoura, Portugal, Sep. 6-9, 2008, Paper PD.3.13.

[13] A. Tessarolo, C. Bassi, D. Giulivo. "Time-stepping finite-element analysis of a 14-MVA salient-pole shipboard alternator for different damper winding design solution," IEEE Trans. Industrial Electronics, vol. 59, no. 6, pp. 2524-2535, June 2012.

[14] A. Schwery, G. Traxler-Samek, E. Schmidt. "Application of a transient finite element analysis with coupled circuits to calculate the voltage shape of a synchronous generator," Proc. CEFC, 2002, pp. 92-95.

[15] De-wei Zhang, Yuan-jun Peng, Zhen-nan Fan. "No-load voltage waveform optimization and rotor heat reduction of tubular hydro-generator," presented at the Int. Conf. Electrical Machines and Systems (ICEMS), Beijing, China, Aug. 20-13, 2011, pp. 1-6.

[16] G. Traxler-Samek, T. Zichermann, A. Schwery. "Cooling airflow, losses and temperatures in large aircooled machines," IEEE Trans. Ind. Electron., vol. 57, no. 1, pp. 172-180, Jan. 2010. 